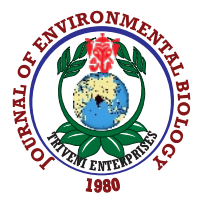

\title{
Impact of sulphur dioxide generating pads and liners on enhancing market acceptability and post-harvest life of grapes
}

\author{
N.K. Arora*, R. Arora and G. Kaur \\ Department of Fruit Science, Punjab Agricultural University, Ludhiana-141004, India \\ *Corresponding Author Email : gagandeep-kps@pau.edu
}

\section{Abstract}

Aim: To identify most suitable packaging material combination consisting of sulphur dioxide $\left(\mathrm{SO}_{2}\right)$ generating pads for cold storage of grapes cv. Perletteto achieve longer storage life.

Methodology: Treatments included packing of grape bunches in low density polyethylene (LDPE) film with single sheet of $\mathrm{SO}_{2}$ generating pad, LDPE with double sheet of $\mathrm{SO}_{2}$ generating and LDPE without $\mathrm{SO}_{2}$ generating pad and all these were further placed in Corrugated Fibre Board (CFB) boxes. In case of control, fruits were kept in CFB lined with newspaper only.

Results: The use of $\mathrm{SO}_{2}$ pads on berries of Perlette grapes stored under varying cold storage environments with different packaging showed significant improvements in post-harvest life. LDPE packaging with single and double sheet of $\mathrm{SO}_{2}$ generating pad expressed the lowest berry shattering and spoilage. The said combination had profound impact on prevention of stem browning of bunches. Physiological loss of weight of stored berries was minimum for LDPE packaging with single sheet of $\mathrm{SO}_{2}$ generating pads $(1.56 \%)$. No differences were observed among the treatments with respect to other physico-chemical evaluations.

Interpretation: The present investigations implicated that the detrimental effects on physico-chemical attributes of grape berries under cold storage can be lessened by synergistic utilization of single sheet of sulphur dioxide generating pads and low-density polyethylene packaging.

Key words: Berry shattering, Corrugated fibre board, Grapes, Post-harvest life, Sulphur-di-oxide, Vitis vinifera

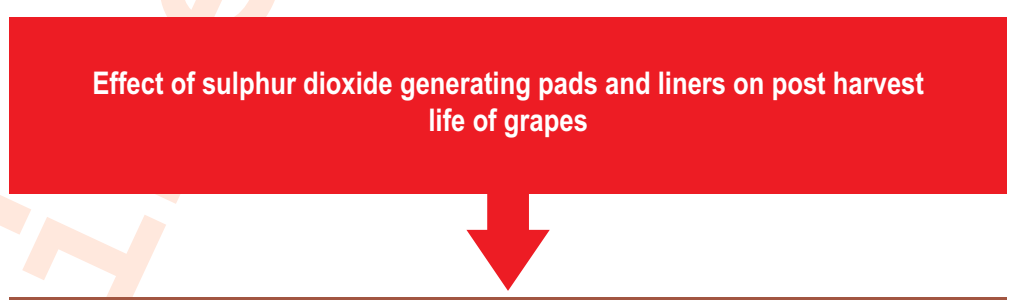

Grapes packed in CFB boxes with LDPE film with single/double sheet of

\section{$\mathrm{SO}_{2}$ generating pad}

Reduced PLW, Spoilage and berry shattering
Acceptable sensory quality upto 30 days of storage

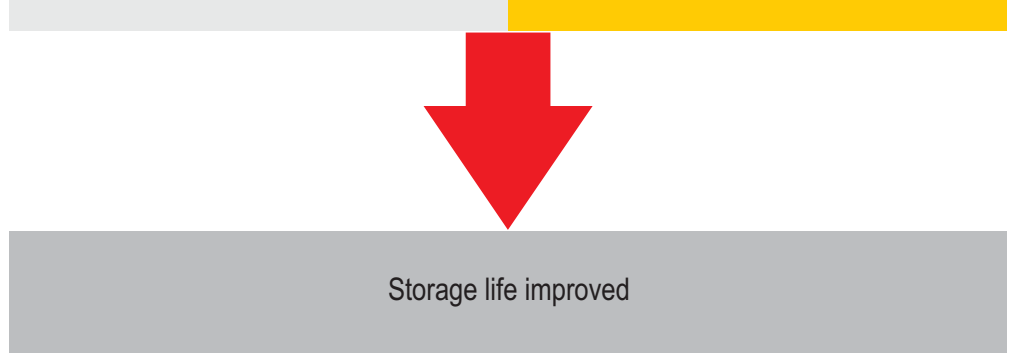

How to cite : Arora, N.K., R. Arora and G. Kaur : Impact of sulphur dioxide generating pads and liners on enhancing market acceptability and post-harvest life of grapes. J. Environ. Biol., 41, 1741-1747 (2020). 


\section{Introduction}

Viticulture is being practiced on $7.71 \mathrm{~m}$ ha land with a production of around $87.4 \mathrm{~m}$ metric tons (FAOSTAT,2017) and is the chief horticultural industry in the world. Among the world's fresh fruit production, table grapes rank $4^{\text {th }}$ after citrus, banana and apple. The quality of harvested table grapes is of prime consideration for domestic as well as international markets. The harvested grape berries are prone to prompt visual detrimental changes owing to fleshy nature of the fruit, high moisture content and titratable acidity of the fruits. The market acceptability of fruits starts deteriorating immediately after harvest and continues until marketing. The harvested berries undergo changes like physiological loss in weight, changes in berry colour, accelerated softening and ripening of berries (Piazzolla et al., 2016). A common consumer identifies better grape bunches in the market by visualizing the berry quality and colour of the rachis (that provide structural support and enables solute transport to the berries). Immediately after harvesting, the rachis starts to turn brown, which affects the overall cluster quality (Silva-Tanzani et al., 2016). The rachis browning is known to be associated with water loss (Crisosto et al., 2001) and oxidation of berries (Carvajal-Millan et al., 2001).Being non-climacteric in nature, the grapes must be harvested at proper stage of maturity in terms of TSS, fruit weight, acidity and other visual marketable and sensory characteristics (Gomez etal., 1995).

In Indian plains, Perlette occupies more than 90 per cent of the total area under grapes. Seedless berries, high productivity and early ripening contribute to higher economic returns to the growers vis-à-vis their preference for this variety. However, due to fear of early rains, very short period (last week of May to $2{ }^{\text {nd }}$ week of June) is available for harvesting. Moreover, being a perishable fruit, it cannot withstand high temperature prevailing at the time of harvesting, thus leading to gluts in the nearby market vis-à-vis low price to the growers. Therefore, to avoid this panic situation it is desirable to store grapes at low temperature after harvesting to prolong its marketing period, thus ensuring good return to the growers.

The harvested grape berries have extremely low physiological activity thus they are very sensitive to water loss and infestation of graymold (Botrytis cinerea) during post-harvest handling and cold storage (Palou et al., 2010). Even grapes stored at most optimum cold storage temperature of $-0.5^{\circ} \mathrm{C}$ and relative humidity of 95 per cent are prone to berry cracking, particularly graymold which is the most aggressive disease owing to its ability to flourish at low temperature (Liguori et al., 2015). Therefore, along with cold storage, there is an imperative need to utilize additional processing aid chemicals like sulphur dioxide, however, the direct exposure to $\mathrm{SO}_{2}$ has been banned in most countries (Sortino et al., 2017). Moreover, $\mathrm{SO}_{2}$ treatment may lead to colour bleach of the berries and surface cracks (Gao et al., 2003).To overcome these discrepancies, the use of sulphur dioxide generator pads in varying packaging material along with cold storage is being experimented worldwide because of their efficiency, ease of use, cheaper cost and low health risk as compared to direct exposure to fungicides (Melgarejo-Flores et al., 2013).

The present investigations were, therefore, planned with the objective of identifying most suitable packaging material in combination with $\mathrm{SO}_{2}$ generating pads for cold storage of most commonly grown Perlette grapes to achieve higher shelf life by preserving the physical and chemical attributes of grape berries to enhance the consumer preference and market acceptability of fruits.

\section{Materials and Methods}

The experimental vines were grown at Fruit Research Farm, Department of Fruit Science, Punjab Agricultural University, Ludhiana, Punjab (India) situated at $30.9^{\circ} \mathrm{N}$ latitude, $75.8^{\circ} \mathrm{E}$ longitude, $249 \mathrm{~m}$ above $\mathrm{msl}$. The study was conducted for the period of three consecutive years $(2015,2016$ and 2017) on grape cultivar Perlette. The soil of the experimental site was alluvial having sandy loam texture and good water holding capacity. The uniform cultural practices (Anonymous, 2019) were followed for the experimental vines for keeping them in good and healthy condition. Fully ripe bunches of grapes having uniform size and disease free berries were picked randomly from all the four directions of experimental vines with the help of secateurs during first week of June. At the time of picking, care was taken to protect the natural bloom layer present on the berries not to be damaged with hands. The bunches were collected in plastic crates and shifted to Post-harvest Laboratory, Department of Fruit Science, Punjab Agricultural University, Ludhiana. In the laboratory, bunches were sorted, graded and were divided into requisite lots for further handling.

Treatments: The present study comprised of four treatments with different combination of packaging materials and sulphur-dioxide $\left(\mathrm{SO}_{2}\right)$ generating (slow release) pads. In different treatments, the uniform sized bunches were packed in polymeric films, i.e., LDPE with single sheet of $\mathrm{SO}_{2}$ generating pad $\left(\mathrm{T}_{1}\right)$; LDPE with double sheet of $\mathrm{SO}_{2}$ generating $\left(\mathrm{T}_{2}\right)$ and LDPE without $\mathrm{SO}_{2}$ generating pad $\left(T_{3}\right)$ and all these were further placed in Corrugated Fibre Board (CFB) boxes. In case of control $\left(\mathrm{T}_{4}\right)$, fruits were kept in CFB lined with newspaper only. These packed CFB boxes were kept in walk-in cold chamber at $0-2^{\circ} \mathrm{C}$ temperature and $90-95$ per cent $\mathrm{RH}$ and were analyzed at different storage intervals $(15,30,45$ and 55 days). Three random samples of fruit (each of $4 \mathrm{~kg}$ ) were taken from each treatment before packing for physico-chemical analysis (zero-day storage) of fruits.

Analyses of fruits: The physiological loss in weight (PLW) of bunches was calculated on initial weight basis. The per cent loss in weight after each storage interval was calculated by subtracting 
the final weight from the initial weight of the grapes and then converted into percentage value. The cumulative loss in weight was calculated on fresh weight basis. A 'five-point scale' was used for sensory evaluation of fruits (5-Excellent, 4 -Very good, 3Good, 2- Fair and 1-Poor). At each interval, grapes were rated by a panel of ten judges on the basis of external appearance of berries, texture, taste and flavour. The spoilage percentage of grape berries was calculated on per cent weight basis by measuring the weight of spoiled berries from each box and dividing them by total weight of berries in each box. The berry shattering percentage of grapes was calculated on per cent weight basis by measuring the weight of shattered berries from each box and dividing them by total weight of berries in each box. Stem browning of bunches was rated by a panel of ten judges on the basis of external appearance of the stem in terms of extent of browning. A five-point intensity scale of damage (1- None, 2Slight, 3- Moderate, 4- Severe, 5-Extreme) was used for recording incidence of stem browning (Artes-Hernandez et al., 2006). The chemical attributes, viz. total soluble solids (TSS) and juice acidity were determined from the grape juice at room temperature (AOAC, 2005).

Statistical analysis : The experiment was laid out in randomized complete block design with factorial arrangements and data was analysed using statistical software cpcs1.

\section{Results and Discussion}

In the present investigation, sulphur dioxide pads used to evaluate their efficacy on decay control and their impact on various physico-chemical attributes on grape berries showed significant improvements in post-harvest life as well as quality parameters when stored under cold storage environments.

The per cent berry shattering was recorded at fortnightly interval up to 55 days of storage. $\mathrm{SO}_{2}$ generating pads had a significant impact on reducing the berry shattering throughout the storage period in comparison with control and the interaction between treatments and storage periods was also found to be significant (Fig. 1). Overall, the lowest per cent mean berry shattering $(3.10 \%)$ was recorded in LDPE packaging combined with double sheet of $\mathrm{SO}_{2}$ generating pad, which was at par with 3.41 per cent registered for HDPE packaging and single sheet of $\mathrm{SO}_{2}$ generating pad. The maximum mean berry shattering (11.78 $\%$ ) was observed in control treatment (newspaper lining) at end of 55 days period of storage. As the storage period was advanced, the percent berry shattering showed upward trend in all the treatments with maximum expression of berry shattering in control treatment $(7.53 \%)$ after 30 days of storage. The per cent shattering in LDPE packaging with both single and double lining of $\mathrm{SO}_{2}$ were at par after 30 days of storage ( 0.61 and $0.62 \%$ ) registering about 91.90 and 91.77 per cent improvement over control, respectively. Further, a sharp increase in berry shattering was observed at 45 and 55 days of storage. Similar beneficial effects of $\mathrm{SO}_{2}$ generating pads on physical characteristics have been reported by Mahajan et al. (2010) who recorded lower berry shattering in grapes packed with double sheet of sulphur dioxide generating pad which substantiated the earlier findings of ArtesHernandez et al. (2006) and Zutahy et al., (2008). Bruises and subsequent rotting are the major threats to table grapes after harvest. Storage duration and treatments significantly affected the spoilage percentage (Fig. 2). Spoilage percentage was 0.56 $\%, 0 \%, 5.62 \%$, and $14.33 \%$ for LDPE + Single sheet of $\mathrm{SO}_{2}$ generating pad, LDPE + Double sheet of $\mathrm{SO}_{2}$ generating pad, LDPE Packaging and Control, respectively, on day 30 . With the progression of storage days, the spoilage registered increase in all the treatments and considerable mold growth was observed in all treatments at 45 and 55 days after storage. As rotting in grapes is mainly due to graymold Botrytis cinerea and $\mathrm{SO}_{2}$ being antifungal agent when used in form $\mathrm{SO}_{2}$ generating pad was effective in checking spoilage. The gas released from sulphur pads may have checked the primary disease progress and killed pathogen more efficiently when combined with the liners. These results are in agreement with the previous studies against graymold of stored 'BRS Vitoria' table grapes (Domingues et al., 2018) and clamshell packaged 'BRS Nubia' Seeded Table Grapes (Youssef et al., 2020). Since the release of $\mathrm{SO}_{2}$ from sodium metabisulfite in pads is function of humidity inside the packaging, the role of liners in the performance of slow release $\mathrm{SO}_{2}$-generating pads can be explained by diverse permeability provided by LDPE and newspaper liners, thereby controlling the concentration of gas inside the packaging. Chaves et al. (2019) also reported that efficacy of different $\mathrm{SO}_{2}$-generating pads may vary due to diverse types of polymer films, coating materials and release forms.

The data for rachis browning indicated that polythene film and sulphur dioxide generating pads in synergism were helpful in checking the browning of stem during storage (Table 1). The lowest mean stem browning (2.01) was recorded in LDPE packaging combined with double sheet of $\mathrm{SO}_{2}$ generating pad, which was statistically at par with LDPE packaging along with single sheet of $\mathrm{SO}_{2}$ generating pad (2.13). The highest mean stem browning (3.86) was recorded in control (newspaper lining), followed by only LDPE packaging (3.07). At 30 days of storage, the stem browning registered an improvement of 62 and 58.86 per cent, respectively, over control. The stem of grape cluster consists of several polyphenols, which act as substrate for enzyme polyphenol oxidase (PPO) which has been reported to be responsible for rachis browning (Souquet et al., 2000). Reduced browning with $\mathrm{SO}_{2}$ can be attributed to prevention of phenol oxidation by inhibiting the enzyme polyphenol oxidase (Ricquebourg et al., 1996).

The present investigation revealed that the Perlette grapes packed in polythene with sulphur dioxide generating pads had steady increase in the PLW as compared to control; in which 


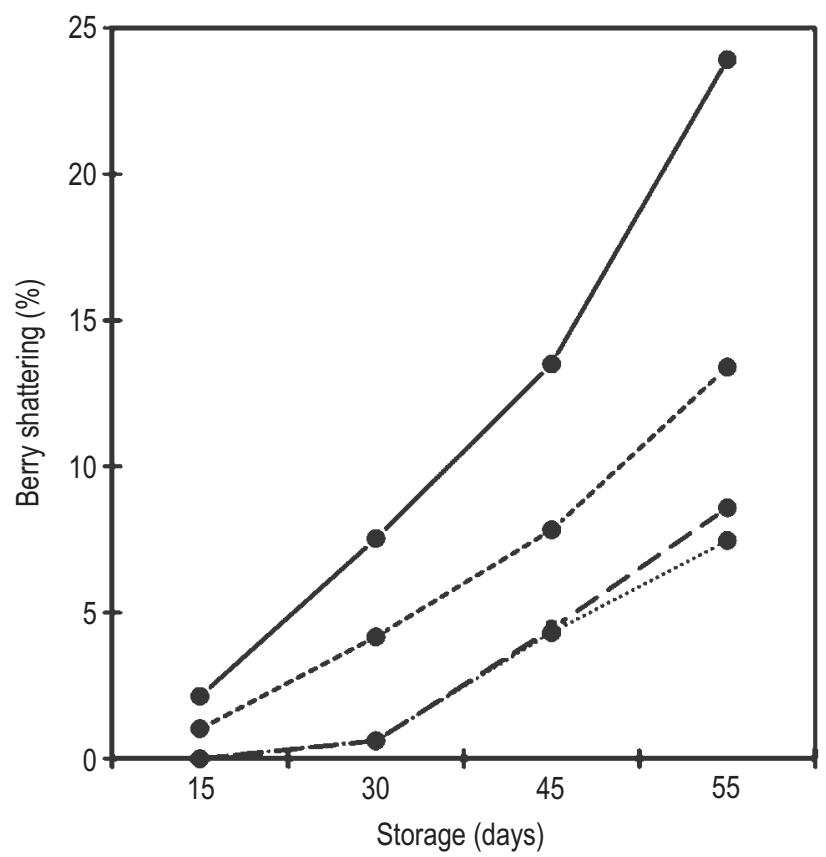

$$
\begin{aligned}
& -\ldots \text { - LDPE Packaging + Single sheet of } \mathrm{SO}_{2} \text { generation pad } \\
& \ldots-\text { LDPE Packaging + Double sheet of } \mathrm{SO}_{2} \text { generation pad } \\
& \ldots \text { Control (newspaper lining only) }
\end{aligned}
$$

Fig. 1 : Effect of packaging materials and sulphur dioxide generating pad on berry shattering in stored Perlette grapes (pooled mean of three years).

faster rise in physiological loss in weight (PLW) was recorded with advancement of storage periods (Table 1). The minimum mean PLW (1.56\%) was observed in grapes packed in LDPE with single sheet of sulphur dioxide generating pads, while the maximum mean PLW (8.42\%) was recorded in grapes packed with newspaper lining (control). Up to 30 days of storage, the PLW depicted by fruits packed in LDPE with single lined $\mathrm{SO}_{2}$ pads was minimum, followed by LDPE with double lining (1.44 and 1.97\%, respectively). The interaction effects were observed to be significant for varying treatments over different storage intervals. The method applied in this study minimizes water loss leading to berry desiccation, and prevents both decay due to low level of $\mathrm{SO}_{2}$, and $\mathrm{SO}_{2}$ damage which occurs if $\mathrm{SO}_{2}$ is too high. Owing to low respiration rate and non-climacteric nature of grapes, physiological loss of weight is defined primarily by dehydration of stored berries from fruit surface and is function of relative humidity of packaging bags. Also, mass loss is one of the consequences of Botrytis cinerea incidence in table grapes (Celik et al., 2009). Thus, packaging using the LDPE with $\mathrm{SO}_{2}$ pads was effective in checking weight loss owing to spoilage control and providing a constant sealed storage condition for grapes. These findings are substantiated by the previous studies of Lichter et al. (2006); Duan et al. (2012) who observed reduction in spoilage in grapes stored in $\mathrm{SO}_{2}$ releasing pads which also contributed towards

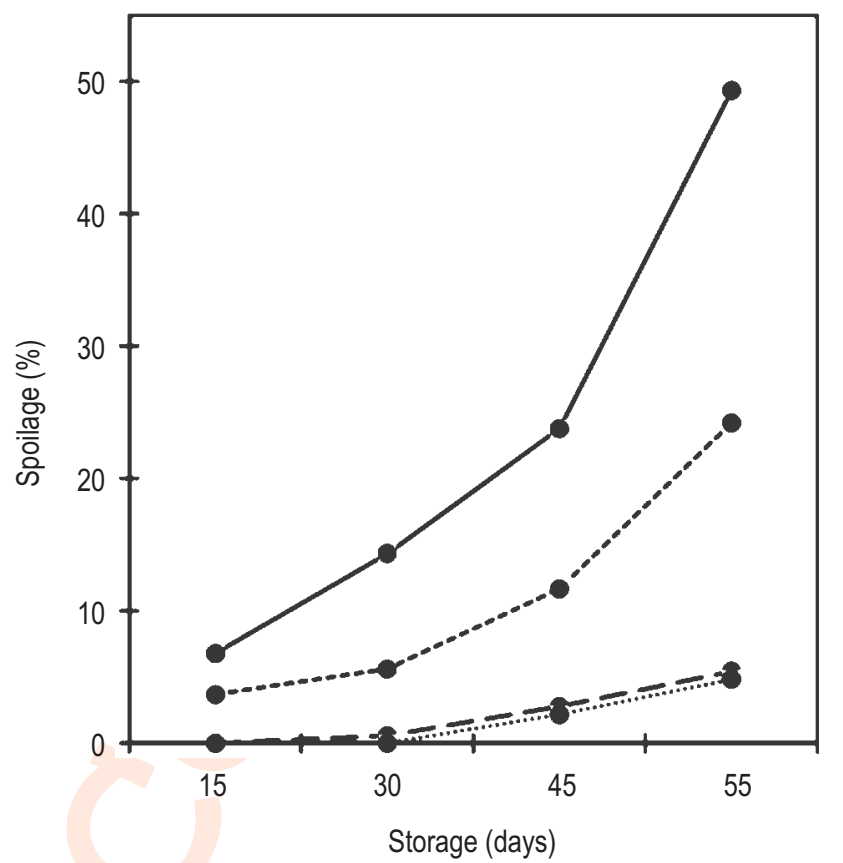

- - - LDPE Packaging + Single sheet of $\mathrm{SO}_{2}$ generation pad

........ LDPE Packaging + Double sheet of $\mathrm{SO}_{2}$ generation pad

----- LDPE Packaging only

$\longrightarrow$ Control (newspaper lining only)

Fig. 2 : Effect of packaging materials and sulphur dioxide generating pad on spoilage in stored Perlette grapes (pooled mean of three years).

decrease in PLW. Grapes packed with LDPE lining having single sheet of sulphur dioxide generating pad showed the most acceptable value of organoleptic rating (4) after 30 days of storage as compared to other treatments (Table 1). Whereas, grapes packed in LDPE polythene with double sheet of sulphur dioxide showed bleaching effect of sulphur and taste of berries also deteriorated. In control (newspaper lining), organoleptic rating score was reduced to 3 after 15 days of storage and found only 1.67 (below fair) after 30 days of storage and thereafter declined at faster pace. Maintenance in physical attributes of Perlette grapes with sulphur dioxide releasing pads can be ascribed to the fact that $\mathrm{SO}_{2}$ fumes released by pads react with water content of stored grapes resulting in formation of sulfurous acid $\left(\mathrm{H}_{2} \mathrm{SO}_{3}\right)$. The $\mathrm{pH}$ content of stored product is lowered and released $\mathrm{H}_{2} \mathrm{SO}_{3}$ reacts with cell membranes of the cell wall degrading micro-organisms and block their enzymatic activity by reducing disulfide (-S-S-) linkage (Verma and Joshi, 2006). As a result, the micro-organisms' activity is hindered, which showed significant improvement in visual characteristics, reduction in spoilage, consequently making the fruit more acceptable in market. However, there was decline in organoleptic score after 45 days of storage with $\mathrm{SO}_{2}$ pad which could be due accumulation of $\mathrm{SO}_{2}$ residue in table grape berries due to continuos and slow released of $\mathrm{SO}_{2}$ gas by $\mathrm{SO}_{2}$ pad was confined in sealed packaging 
Table 1 : Effect of packaging materials and sulphur dioxide generating pad on physical attributes of Perlette grapes (pooled mean of three years)

\begin{tabular}{|c|c|c|c|c|c|}
\hline \multicolumn{6}{|c|}{ Stem Browning (1-5 score) ${ }^{*}$} \\
\hline \multirow[t]{2}{*}{ Treatments } & \multicolumn{5}{|c|}{ Storage period (days) } \\
\hline & 15 & 30 & 45 & 55 & Mean \\
\hline LDPE Packaging + Single sheet of $\mathrm{SO}_{2}$ generating pad & 1.00 & 1.44 & 2.56 & 3.5 & 2.13 \\
\hline LDPE Packaging + Double sheet of $\mathrm{SO}_{2}$ generating pad & 1.00 & 1.33 & 2.50 & 3.22 & 2.01 \\
\hline LDPE Packaging only & 2.11 & 2.78 & 3.22 & 4.17 & 3.07 \\
\hline Control (newspaper lining only) & 2.78 & 3.5 & 4.22 & 4.94 & 3.86 \\
\hline Mean & 1.72 & 2.26 & 3.13 & 3.96 & - \\
\hline
\end{tabular}

\section{Physiological loss of weight (\%)}

$\begin{array}{llllll}\text { LDPE Packaging + Single sheet of } \mathrm{SO}_{2} \text { generating pad } & 1.02 & 1.44 & 1.72 & 2.05 & 1.56 \\ \text { LDPE Packaging + Double sheet of } \mathrm{SO}_{2} \text { generating pad } & 1.78 & 1.97 & 2.29 & 2.74 & 2.20 \\ \text { LDPE Packaging only } & 1.44 & 1.82 & 1.98 & 2.17 & 1.82 \\ \text { Control (newspaper lining only) } & 5.21 & 6.74 & 8.83 & 12.89 & 8.42 \\ \text { Mean } & 2.36 & 2.99 & 3.71 & 4.96 & -\end{array}$

$C D(p=0.05)$ for: Storage interval $(A)=0.23 ;$ Treatment $(B)=0.31 ; \operatorname{Interaction}(A \times B)=0.62$

\section{Organoleptic rating*}

\begin{tabular}{llllll} 
LDPE Packaging + Single sheet of $\mathrm{SO}_{2}$ generating pad & 4.0 & 4.00 & 2.67 & 1.0 & 2.91 \\
LDPE Packaging + Double sheet of $\mathrm{SO}_{2}$ generating pad & 4.0 & 3.00 & 2.33 & 1.0 & 2.58 \\
LDPE Packaging only & 3.67 & 2.00 & 1.67 & 1.0 & 2.09 \\
Control (newspaper lining only) & 3.0 & 1.67 & 1.0 & 1.0 & 1.67 \\
Mean & 3.67 & 3.56 & 1.92 & 1.0 & - \\
\hline
\end{tabular}

$\mathrm{CD}(\mathrm{p}=0.05)$ for: Storage interval $(A)=0.22$; Treatment $(B)=0.29$; Interaction $(A \times B)=N S$; *Score: 5 - excellent; 4-very good; 3-good; 2-fair; 1- poor

Table 2 : Effect of packaging materials and sulphur dioxide generating pad on chemical attributes of Perlette grapes (pooled mean of three years)

\begin{tabular}{|c|c|c|c|c|c|}
\hline \multicolumn{6}{|c|}{ Total Soluble Solids (\%) } \\
\hline \multirow[t]{2}{*}{ Treatments } & \multicolumn{5}{|c|}{ Storage period (days) } \\
\hline & 15 & 30 & 45 & 55 & Mean \\
\hline LDPE Packaging + Single sheet of $\mathrm{SO}_{2}$ generating pad & 14.4 & 14.5 & 14.4 & 15.2 & 14.4 \\
\hline LDPE Packaging + Double sheet of $\mathrm{SO}_{2}$ generating pad & 14.2 & 14.6 & 14.5 & 14.5 & 14.5 \\
\hline LDPE Packaging only & 14.5 & 14.6 & 14.4 & 14.4 & 14.5 \\
\hline Control (newspaper lining only) & 14.1 & 15.0 & 14.8 & 14.5 & 14.6 \\
\hline Mean & 14.3 & 14.7 & 14.5 & 14.7 & - \\
\hline \multicolumn{6}{|c|}{$C D(p=0.05)$ for: Storage interval $(A)=N S$; Treatment $(B)=N S$; Interaction $(A \times B)=N S$} \\
\hline \multicolumn{6}{|c|}{ Acidity (\%) } \\
\hline LDPE Packaging + Single sheet of $\mathrm{SO}_{2}$ generating pad & $0.77^{\circ}$ & 0.76 & 0.73 & 0.70 & 0.74 \\
\hline LDPE Packaging + Double sheet of $\mathrm{SO}_{2}$ generating pad & 0.79 & 0.77 & 0.75 & 0.78 & 0.78 \\
\hline LDPE Packaging only & 0.78 & 0.76 & 0.75 & 0.76 & 0.76 \\
\hline Control (newspaper lining only) & 0.81 & 0.73 & 0.73 & 0.75 & 0.76 \\
\hline Mean & 0.78 & 0.74 & 0.74 & 0.73 & - \\
\hline
\end{tabular}

$C D(p=0.05)$ for: Storage interval $(A)=N S ;$ Treatment $(B)=N S ;$ Interaction $(A \times B)=N S$

entered grape berries. The results corroborate with the findings of Jia et al. (2020) who observed that MAP $+\mathrm{SO}_{2}$ pad could lead to high $\mathrm{SO}_{2}$ residue $\left(9.3 \mathrm{mg} \mathrm{kg}^{-1}\right)$ in table grape berries.
To gain maximum economic benefits, it is imperative to preserve the taste and quality of stored fruit, which in grapes is directly dependent on TSS and fruit acidity. These traits were 
evaluated in the present studies under various treatments for different time intervals.

Various treatments showed non-significant differences among themselves with regard to TSS during storage (Table 2). The highest TSS (15.0\%) after 30 days of storage was recorded in control (newspaper lining). The TSS values in all other treatments were at par with each other. Maximum TSS was registered after 55 days of storage (15.2\%) for LDPE packaging + single sheet of sulphur dioxide generating pad. Likewise, the acidity percentage showed non-consistent trend with advancement in storage period (Table 2$)$. The lowest mean acidity $(0.74 \%)$ was recorded in LDPE packaging + single sheet of $\mathrm{SO}_{2}$ generating pad. The highest mean acidity $(0.78 \%)$ was recorded in LDPE packaging + double sheet of $\mathrm{SO}_{2}$ generating pad. The TSS percentage of stored fruit increased initially from 15 to 30 days of storage and consequently decreased or remained consistent as the catabolic processes of stored fruits were lowered by $\mathrm{SO}_{2}$ fumes, however, as the storage period is enhanced, the efficiency of pads is lowered and metabolic changes start in stored fruit (Pelayo et al., 2003). Hence $\mathrm{SO}_{2}$ pads contributed positively towards delaying the reduction in total soluble solids content during first month of storage which can be ascribed to inhibition of respiration due to sulphur dioxide generating pads. Afterwards, the lowering TSS values might be due to increased respiratory activities of grape berries as for this physiological process, sugars (glucose and fructose) are the main substrates (Sortino et al., 2018). The titratable acidity of stored fruit was also preserved over longer storage intervals owing to lower fruit respiration and transpiration under cold storage, thus organic acids which otherwise would have been utilized in catabolism were preserved (Cordenunsi et al., 2003). Similar suppositions on preservation of biochemical characteristics of stored grape clusters have been reported earlier (Fernandez-Trujillo et al., 2008; Meng et al., 2011 and Sortino et al., 2018).

It can be safely implicated from the present evaluations that the detrimental effects on physico-chemical attributes of grape berries under cold storage can be lessened by synergistic utilization of sulphur dioxide generating pads and low-density polyethylene packaging. The 'Perlette' grapes can be harvested at maturity without any perturbing effects of glut in the market and can be stored safely for 30 days in LDPE polyethylene packaging with single lined $\mathrm{SO}_{2}$ generating pads without diminishing the market acceptability. This practice will lead to prolonged storage life of grapes for more than four weeks by storing at low temperature and high humidity, which will ultimately increase the net returns vis-à-vis profitability to majority of grape growers of the region.

\section{References}

Anonymous: Package of Practices for Cultivation of Fruits. Punjab Agricultural University, Ludhiana, pp. 1-178 (2019).
AOAC: Official Methods of Analysis. $18^{\text {th }}$ Edn., Association of Official Analytical Chemists, Washington DC (2005).

Artes-Hernandez, F., F. Tomas-Barberan and F. Artes: Modified atmosphere packaging preserves quality of $\mathrm{SO}_{2}$-free 'Superior seedless' table grapes. Post harv. Biol. Technol., 39, 146-154 (2006).

Carvajal-Millan E., T. Carvallo, J. Orozco, M. Martínez, I. Tapia, V. Guerrero, A. Rascon-Chu and J.A. Llamas: Gardea polyphenol oxidase activity, color changes, and dehydration in table grape rachis during development and storage as affected by $\mathrm{N}$-(2-chloro4-pyridyl)-N-phenylurea, J. Agric. Food Chem., 49, 946-951 (2001).

Celik, M., T. Kalpulov, Y. Zutahy, B. Ish-Shalom, S. Lurie and A. Lichter: Quantitative and qualitative analysis of Botrytis inoculated on table grapes by qPCR and antibodies. Post Harv. Biol. Tech., 52, 235-239 (2009).

Chaves, O.J.Jr., K. Youssef, R. Koyama, S. Ahmed, A.R. Dominguez, D.T. Mühlbeier and S.R. Roberto: Control of graymold on clamshell-packaged 'Benitaka' table grapes using sulphur dioxide pads and perforated liners. Pathogens, 8, 271(2019).

Cordenunsi, B.R., J.R.O. Nascimento and F.M. Lajolo: Physicochemical changes related to quality of five strawberry fruit cultivars during cool storage, Food Chem.,83,167-183 (2003).

Crisosto C.H., J.L. Smilanick and N.K. Dokoozlian: Table grapes suffer water loss, stem browning during cooling delays. Calif. Agric., 55, 39-42 (2001).

Domingues, A.R, S.R. Roberto, S Ahmed, M Shahab, O.J. Chaves Junior, C.H. Sumida and R.T. Souza: Post harvest techniques to prevent the incidence of botrytis mold of 'BRS Vitoria' seedless grape under cold storage. Horti., 4, 17 (2018)

Duan, H., W. Xu, D. Li, Y. Fu and J. Zhang: Analysis of application of environmental properties of $\mathrm{SO}_{2}$ fungicide for extended storage life of Muscate table grapes at room temperature. Adv. Mater. Res., $600,33-38$ (2012).

FAOSTAT: Statistical database of the Food and Agricultural Organization of the United Nations. (2017).

Fernandez-Trujillo, J.P., J.M. Obando-Ulloa, R. Baro and J.A. Martínez: Quality of two table grape guard cultivars treated with single or dual-phase release $\mathrm{SO}_{2}$ generators. J. Appl. Bot. Food Qual., 82, 1-8 (2008).

Gao, H., X. Hu, H. Zhang, S. Wang and L. Liu: Study on sensitivity of table grapes to $\mathrm{SO}_{2}$. Acta Hort., 628, 541-548 (2003).

Gomez, E., A. Martínez and J. Laencina: Changes in volatile compounds during maturation of some grape varieties. J. Sci. Food Agric., 67, 229-233(1995).

Jia, X., X. Hao, Y. Zheng, J. Zhang, Y. Li, X. Li and Z. Zhao: Storage quality of "Red Globe" table grape (Vitis vinifera L.): Comparison between automatic periodical gaseous SO2 treatments and MAP combined with $\mathrm{SO}_{2}$ pad. J. Food Process Preserv., e14507 (2020). https://doi.org/10.1111/jpp. 14507

Lichter, A., F.M. Gabler and J.L. Smilanick: Control of spoilage in table grapes. Stewart Postharv. Rev., 2, 1-10 (2006).

Liguori, G., G. Sortino, C. De Pasquale and P. Inglese: Effects of modified atmosphere packaging on quality parameters of minimally processed table grapes during cold storage. Adv. Hort. Sci., 29, 152-154 (2015).

Mahajan, B.V.C., N.K. Arora, M.I.S. Gill and B.S. Ghuman: Studies on extending storage life of Flame Seedless grapes. J. Hort. Sci. Orna. Pl., 2, 88-92 (2010). 
Melgarejo-Flores, B.G., L.A. Ortega-Ramírez, B. A. Silva-Espinoza, G.A. González-Aguilar, M.R.A. Miranda and J.F. Ayala-Zavala: Antifungal protection and antioxidant enhancement of table grapes treated with emulsions, vapors, and coatings of cinnamon leaf oil. Post Harv. Biol. Technol., 86, 321-328 (2013).

Meng, Z., W. Chunsheng, L. Jianhua and Z. Lixin: Effects of $\mathrm{SO}_{2}$ dual release on the storage quality of Red Globe grape. J. Fruit Sci., 28, 685-688 (2011)

Palou, L., M. Serrano, D.M. Romero and D. Valero: New approaches for post harvest quality retention of table grapes. Fresh Produce, 4, 103-110(2010).

Pelayo, C., S.E. Ebeler and A.A. Kader: Post harvest life and flavor quality of three strawberry cultivars kept at $50 \mathrm{C}$ in air or air $+20 \mathrm{kpa}$ $\mathrm{CO}_{2}$. Postharv. Biol. Technol., 27, 171-183 (2003).

Piazzolla, F., S. Pati, M.L. Amodio and G. Colelli: Effect of harvest time on table grape quality during on vine storage. J. Sci. Food Agric., 96, 131-139 (2016)

Ricquebourg, S.L., M.F. Christine, C.C. Rouch and F.R. Cadet: Theoretical support for a conformational change of polyphenol oxidase induced by metabisulfite. J. Agric. Food Chem., 44, 34573460 (1996).
Silva-Sanzana, C., I. Balica, P. Sepulvedaa, P. Olmedoa, G. Leona, B.G. Defilippi, F. Blanco-Herreraa and R. Campos-Vargasa: Effect of modified atmosphere packaging (MAP) on rachis quality of 'Red Globe' table grape variety. Post Harv. Biol. Tech., 119, 33-40 (2016).

Sortino, G., A. Allegra, R. Passafiume, G. Gianguzzi, G. Gullo and A. Gallotta: Post harvest application of sulphur dioxide fumigation to improve quality and storage ability of "Red Globe" grape cultivar during long cold storage. Chem. Eng. Trans., 58, 4034-4038 (2017).

Sortino, G., V. Farina, A. Gallotta and A. Allegra: Effect of low $\mathrm{SO}_{2}$ post harvest treatment on quality parameters of 'Italia' table grape during prolonged cold storage. Acta Hort., 1194, 695-700. (2018)

Verma, L.R. and V.K. Joshi: Post harvest technology of fruits and vegetables. Indus Publishing Company, New Delhi (2006).

Youssef, K., O.J.C. Junior, D.T. Muhlbeier and S.R. Roberto: Sulphur dioxide pads can reduce graymold while maintaining the quality of clamshell-packaged 'BRS Nubia' seeded table grapes grown under protected cultivation. Horti., 6, 20 (2020).

Zutahy, Y., A. Lichter, T. Kaplunov and S. Lurie: Extended storage of 'Red Globe' grapes in modified $\mathrm{SO}_{2}$ generating pads. Post Harv. Biol. Technol., 50, 12-17 (2008). 